\title{
Caffeine and Coffee as Therapeutics Against Alzheimer's Disease
}

\author{
Gary W. Arendash ${ }^{\mathrm{a}, \mathrm{b}, *}$ and Chuanhai Cao ${ }^{\mathrm{b}, \mathrm{c}}$ \\ ${ }^{a}$ The Florida Alzheimer's Disease Research Center, Tampa, FL, USA \\ ${ }^{\mathrm{b}}$ Department of Cell Biology, Microbiology, and Molecular Biology, University of South Florida, Tampa, FL, USA \\ 'The Byrd Alzheimer's Center and Research Institute, Tampa, FL, USA
}

\begin{abstract}
Epidemiologic studies have increasingly suggested that caffeine/coffee could be an effective therapeutic against Alzheimer's disease (AD). We have utilized a transgenic mouse model for AD in well-controlled studies to determine if caffeine and/or coffee have beneficial actions to protect against or reverse AD-like cognitive impairment and AD pathology. AD mice given caffeine in their drinking water from young adulthood into older age showed protection against memory impairment and lower brain levels of the abnormal protein (amyloid- $\beta$; $\mathrm{A} \beta$ ) thought to be central to AD pathogenesis. Moreover, "aged" cognitively-impaired AD mice exhibited memory restoration and lower brain $\mathrm{A} \beta$ levels following only 1-2 months of caffeine treatment. We believe that the cognitive benefits of chronic caffeine administration in AD mice are due to caffeine itself, and not metabolites of caffeine; this, because our long-term administration of theophylline to AD mice provided no cognitive benefits. In acute studies involving $\mathrm{AD}$ mice, one oral caffeine treatment quickly reduced both brain and plasma $\mathrm{A} \beta$ levels - similarly rapid alterations in plasma $\mathrm{A} \beta$ levels were seen in humans following acute caffeine administration. "Caffeinated" coffee provided to $\mathrm{AD}$ mice also quickly decreased plasma A $\beta$ levels, but not "decaffeinated" coffee, suggesting that caffeine is critical to decreasing blood $\mathrm{A} \beta$ levels. Caffeine appears to provide its disease-modifying effects through multiple mechanisms, including a direct reduction of $\mathrm{A} \beta$ production through suppression of both $\beta$ - and $\gamma$-secretase levels. These results indicate a surprising ability of moderate caffeine intake (the human equivalent of $500 \mathrm{mg}$ caffeine or 5 cups of coffee per day) to protect against or treat AD in a mouse model for the disease and a therapeutic potential for caffeine against $\mathrm{AD}$ in humans.
\end{abstract}

Keywords: Alzheimer's disease, amyloid- $\beta$, caffeine, coffee, memory

\section{INTRODUCTION}

The premise that caffeine/coffee may provide a safe, effective, readily available, and inexpensive therapeutic against Alzheimer's disease (AD) is underscored by a growing body of epidemiological literature. Several cross-sectional human studies have reported that caffeine/coffee consumption in both young and aged normal adults is associated with better cognitive performance [1,2]. Caffeine/coffee has been shown to improve information processing in the elderly, as well as

${ }^{*}$ Correspondence to: Gary W. Arendash, Ph.D., Department of Cell Biology, Microbiology, and Molecular Biology, University of South Florida, Tampa, FL 33620, USA. Tel.: +1 813974 1584; Fax: +1813974 1614; E-mail: arendash@cas.usf.edu. in young adults [3]. In a 10-year prospective study involving aging men, Van Gelder et al. [4] found that coffee consumption was linked to slower cognitive decline, particularly with modest coffee consumption of 3 cups per day (approximately $300 \mathrm{mg}$ caffeine). More recently, women with higher coffee consumption over a four year period showed less cognitive decline than those consuming little or no coffee [5] and mid-life coffee consumption has been linked to a $65 \%$ decreased risk of AD [6]. Most convincing of the epidemiologic studies in establishing an association between caffeine and AD has been Maia and de Mendonca [7], which reported that AD patients consumed markedly less caffeine during the 20 years preceding diagnosis of $\mathrm{AD}$, compared with age-matched individuals without AD. Although these epidemiologic studies collectively suggest that chronic caffeine/coffee intake delays or reduces the 
risk of $\mathrm{AD}$, the extent to which caffeine/coffee protects against $\mathrm{AD}$ is problematic to assess in humans because: 1) retrospective studies are based on recall and cannot unequivocally isolate caffeine/coffee intake from other factors affecting cognition over years, and 2) controlled longitudinal studies involving caffeine/coffee administration over decades are impractical. Moreover, the potential for caffeine/coffee to treat established cases of $\mathrm{AD}$ has not been reported to date in the scientific literature.

The aforementioned issues concerning epidemiologic, longitudinal, and controlled studies in humans to evaluate the therapeutic potential of caffeine/coffee against $\mathrm{AD}$ are at least partially addressed by human amyloid- $\beta$ protein precursor $(\mathrm{A} \beta \mathrm{PP})$ transgenic mouse models for AD. These AD mice bear one or more human genetic mutations that cause the familial form of AD. One such mutation is the "Swedish" mutation, resulting in a double amino acid substitution at the $\beta$ secretase cleavage site of $\mathrm{A} \beta \mathrm{PP}$, making such cleavage much more likely and thus greatly increasing production of human $\mathrm{A} \beta$ in brains of these transgenic mice. The human $\mathrm{A} \beta$ that is produced then aggregates into the $\mathrm{A} \beta$ cores of neuritic plaques, as in human brains. During the process of $\mathrm{A} \beta$ aggregation, these "A $\beta$ PPsw" mice become cognitively impaired in a variety of cognitive domains [8-10], similar to human AD patients. Although $\mathrm{A} \beta$ PPsw mice are only a model for the $\mathrm{A} \beta$ deposition of $\mathrm{AD}$ (and do not mimic the full pathologic complexity of the human disease), they do model what is thought to be the primary disease mechanism $\mathrm{A} \beta$ production and aggregation in the brain. As such, highly controlled studies can be done by utilizing these mice to develop insight into what therapeutics could protect against or treat AD in humans. This paper provides a brief overview of the studies we have performed with $\mathrm{AD}$ transgenic mice to evaluate the potential of caffeine/coffee for protection and treatment against $\mathrm{AD}$ in humans. As well, we mention initial results from our on-going clinical studies involving caffeine administration.

\section{MATERIALS AND METHODS}

The Materials and Methods for the studies/data involving caffeine administration have been described in detail in our previous work [11-13], which is referred to specifically when a particular study is presented and discussed. For our new behavioral study involving long-term theophylline administration to AD mice, appropriate methods are included in the section detailing results of that study.

\section{RESULTS}

Caffeine to protect against Alzheimer's disease: transgenic mouse studies

Our initial studies were designed to determine whether caffeine could protect against the development of $\mathrm{A} \beta$ neuropathology and cognitive impairment in A $\beta$ PPsw transgenic mice. In those studies, which are detailed in Arendash et al. [11], we put caffeine into the drinking water of $\mathrm{A} \beta \mathrm{PPsw}$ transgenic $(\mathrm{Tg})$ mice between 4 and 9 months of age $(300 \mathrm{mg} / \mathrm{L})$. The resultant amount of caffeine intake for each mouse (approximately $1.5 \mathrm{mg} /$ day) was the human equivalent of $500 \mathrm{mg}$ or 5 cups of coffee per day. Cognitive testing in a comprehensive battery during the final 6 weeks of treatment revealed surprisingly better performance of $\mathrm{Tg}$ mice being given caffeine compared to control Tg mice given non-caffeinated water. In caffeinetreated Tg mice, cognitive domains of spatial learning/reference memory, working memory, and recognition/identification were in fact at or near the performance level of non-transgenic control mice, which were being given water. Even when "overall" cognitive performance was assessed by evaluating many cognitive measures collectively in discriminant function analysis (DFA), the superior overall performance of caffeine-treated Tg mice could easily be distinguished from the overall performance of Tg controls. Thus, long-term caffeine treatment protected AD mice from cognitive impairment overall and in multiple cognitive domains.

There are several reasons why caffeine-induced cognitive protection in AD Tg mice is unlikely to involve generalized mechanisms (e.g., increased glucose utilization) and/or the well-known stimulant effects of caffeine to increase alertness/focus. First, long-term caffeine administration had no effect on sensorimotor or anxiety function in such Tg mice [11]. Second, we have found that life-long administration of caffeine in drinking water to normal (non-transgenic) mice does not improve their cognitive performance when tested in older age [12].

Accompanying the cognitive protection provided by long-term caffeine treatment to $\mathrm{Tg}$ mice, there were significant $32-37 \%$ reductions in their hippocampal (brain) levels of $\mathrm{A} \beta$ compared to untreated $\mathrm{Tg}$ mice [11]. Importantly, the mechanism for this caffeineinduced reduction in brain $\mathrm{A} \beta$ involves suppression of A $\beta$ production because both $\beta$ - and $\gamma$-secretase levels were reduced in the hippocampus of caffeine-treated 


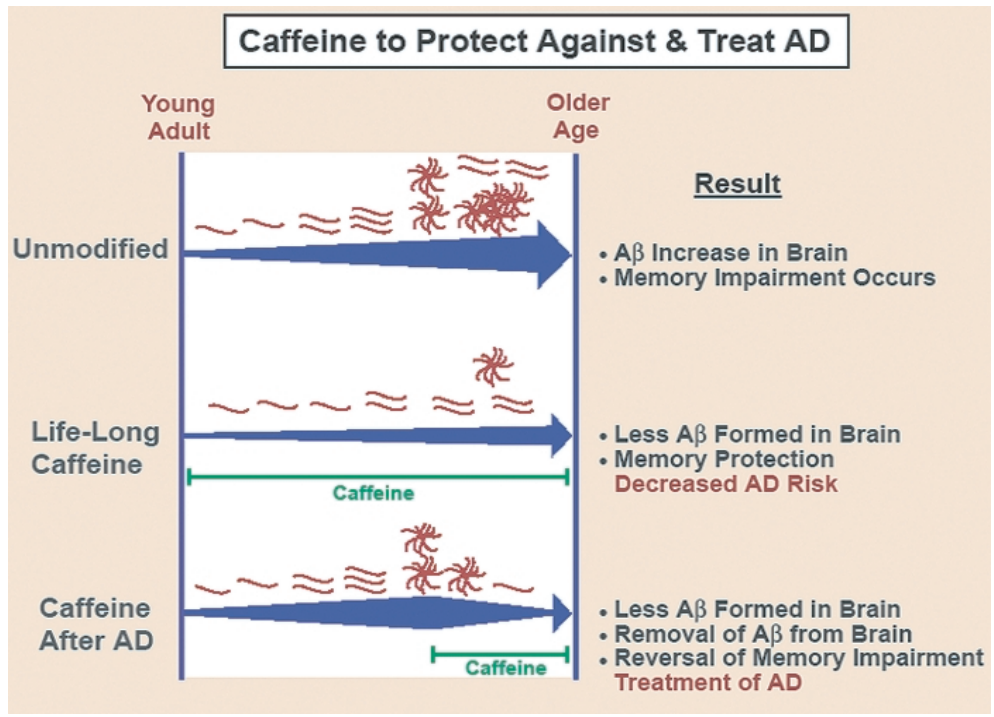

Fig. 1. Protective/treatment effects of caffeine intake on $\mathrm{A} \beta$ production/aggregation and memory in AD transgenic (Tg) mice when caffeine consumption is started during young adulthood (life-long caffeine) or after development of AD pathology/memory impairment.

Tg mice [11]. Exactly how caffeine suppresses both of these secretases was explored in our follow-up studies (see next section). Our initial study [11] provided the first evidence that caffeine can directly affect AD pathogenesis by suppressing levels of both enzymes needed for $\mathrm{A} \beta$ production. Moreover, we have shown that this suppression of $\mathrm{A} \beta$ production by caffeine occurs at physiologic concentrations $(1-10 \mu \mathrm{M})$ - caffeine concentrations that are present in the plasma and brain following only 1-2 cups of coffee. Parenthetically, we are not aware of any AD drug under development by the pharmaceutical industry that has caffeine's profound ability to reduce both $A \beta$ - producing enzymes. As depicted in Fig. 1, "unmodified" brain $\mathrm{A} \beta$ production and aggregation during aging in $\mathrm{Tg}$ mice inevitably results in memory impairment. By contrast, long-term ("life-long") caffeine intake to $\mathrm{Tg}$ mice reduces brain $\mathrm{A} \beta$ production/aggregation, thus protecting against development of $\mathrm{A} \beta$-induced memory impairment (Fig. 1).

\section{Caffeine to treat Alzheimer's disease: transgenic mouse studies}

To determine if caffeine treatment has the ability to reduce pre-existing memory impairment and $\mathrm{A} \beta$ neuropathology, caffeine treatment in drinking water (300 mg/L) was administered for 2 months to "aged" Tg mice already exhibiting both of these AD characteristics [12]. This concentration of caffeine in drinking water, which is identical to that utilized in our prior protection-based study, results in mice receiving a daily caffeine intake of approximately $1.5 \mathrm{mg} /$ day (e.g., the human equivalent of $500 \mathrm{mg}$ caffeine or 5 cups of coffee per day). Prior to caffeine treatment, aged Tg mice were substantially impaired in a working memory task, the radial arm water maze. Following caffeine treatment, however, these same mice exhibited a restoration of working memory to the level of normal, aged mice [12]. In these same aged $\mathrm{Tg}$ mice, which had substantial brain $\mathrm{A} \beta$ deposition prior to caffeine treatment, reductions of $40 \%$ and above for both soluble and deposited (insoluble) brain $\mathrm{A} \beta$ were evident following caffeine treatment [12].

The profound cognitive restoration by caffeine in aged AD mice is likely due to caffeine's aforementioned ability to reduce $\mathrm{A} \beta$ production by reducing both $\beta$ - and $\gamma$-secretase protein expression [11]. We have further extended these mechanistic findings by showing that 1) caffeine administration to $\mathrm{Tg}$ mice was able to reduce the Raf-1/NF $\kappa \mathrm{B}$ inflammatory pathway, which stimulates brain $\beta$-secretase, and 2) caffeine suppresses both $\alpha$ and $\beta$ isoforms of GSK-3 in neuronal cell cultures, which are linked to PS $1 / \gamma$-secretase activity and tau hyperphosphorylation, respectively. Regarding suppression of the Raf-1 inflammatory pathway, we have determined that caffeine stimulates PKA activity in the hippocampus of treated AD Tg mice [12]. This enhanced PKA activity then inhibits (inactivate) cRaf1 by phosphorylation at serine 259 , decreasing $\mathrm{NF} \kappa \mathrm{B}$ activity and the expression of $\mathrm{NF} \kappa \mathrm{B}$-controlled genes such as BACE1, thus resulting in decreased $\mathrm{A} \beta$ pro- 
duction. Regarding the suppression of GSK-3, caffeine affects both active and holoprotein (total) GSK-3 levels [12], which suggests that caffeine does not diminish GSK-3 activity through direct substrate-level phosphorylation, but rather through alternations in protein production or degradation The extent to which either or both of these caffeine mechanisms involve adenosine receptor antagonism is unknown and currently being investigated.

Our measurement of plasma caffeine levels of aged, behaviorally-evaluated $\mathrm{A} \beta \mathrm{PPsw}$ mice given two months of caffeine treatment underscores the human relevance and physiologic significance of the caffeine treatment in this long-term study. At the caffeine concentration in drinking water that was employed, plasma caffeine levels averaged $26 \mu \mathrm{M}$ [13], equivalent to the plasma caffeine concentration expected in humans following intake of several cups of coffee. This caffeine concentration is very close to the $20 \mu \mathrm{M}$ concentration that we found to be optimal in our cell culture studies for suppression of $\mathrm{A} \beta_{1-40}$ and $\mathrm{A} \beta_{1-42}$ production, although caffeine concentrations in the much lower $\mathrm{nM}$ range (250-500 $\mathrm{nM}$ caffeine) were also effective [11]. This very low $\mathrm{nM}$ range of caffeine effectiveness to reduce $\mathrm{A} \beta$ production in vitro is below the level of any known molecular target, including adenosine receptor antagonism. As such, caffeine's reduction of $\mathrm{A} \beta$ production appears to be novel in being independent of adenosine receptors actions. It is important to note that theophylline, one of several active metabolites of caffeine, may be responsible for at least some of the cognitive, neuropathologic, and neurochemical benefits of caffeine. This premise is underscored by the fact that caffeine metabolites such as theophylline have a considerably longer half-life than caffeine. We have explored the contribution of theophylline to the benefits currently being attributed to caffeine in our AD mice, and report our findings in the next section.

Also in this long-term caffeine treatment study in aged $\mathrm{AD}$ mice, we found a clear reduction in hippocampal inflammatory cytokines in caffeine-treated mice with higher plasma caffeine levels compared to those with lower caffeine levels. The ability of caffeine to provide beneficial anti-inflammatory effects in the brains of $\mathrm{AD}$ mice is consistent with prior studies supportive of its anti-inflammatory capacities [14] and, as such, could represent a potent "non-amyloidogenic" mechanism of caffeine action that may contribute to its ability to protect against/reverse cognitive impairment. Other beneficial mechanisms of caffeine action in $\mathrm{AD}$ mice (and perhaps in human $\mathrm{AD}$ ) include the antioxidant actions of caffeine [15], its ability to block disruptions of the blood-brain barrier [16], and its well-established antagonism of brain A1 and/or A2A adenosine receptors $[1,2,17,18]$. Regarding the latter, adenosine receptor antagonism may be central to most or all of the beneficial actions of caffeine against AD. Any combination of such mechanisms of caffeine action may collectively provide the cognitive benefits we have documented in AD mice.

The effects of caffeine on established AD characteristics are summarized in Fig. 1 (Caffeine after AD), which shows caffeine-induced suppression of $\mathrm{A} \beta$ production leading to removal of $\mathrm{A} \beta$ from the brain, resulting in reversal of cognitive impairment. This study [12], performed in aged AD mice, provides the first evidence that caffeine treatment can reverse cognitive impairment and AD neuropathology in a model for the disease.

\section{Theophylline and cognitive function in AD transgenic mice}

As a major active metabolite of caffeine, theophylline may be responsible for a significant part of the cognitive benefits we found through long-term caffeine administration. In the aged $\mathrm{Tg}$ mouse study just presented [12,13], we found plasma theophylline levels to be strongly correlated with plasma caffeine levels. Moreover, theophylline has a longer half-life than caffeine, with brain concentrations of theophylline usually being higher than those for caffeine following longterm caffeine treatment [19]. Thus, it is important to determine the extent to which theophylline, contributes to the cognitive benefit we are attributing to caffeine administration in our AD mice. We therefore administered theophylline in drinking water $(200 \mathrm{mg} / \mathrm{L})$ to A $\beta$ PPsw+PS 1 double transgenic mice (Jackson Laboratories, Bar Harbor, Maine) or non-transgenic littermates beginning at 5.5 months of age. The resulting dose of theophylline (approximately $1 \mathrm{mg} /$ day) is just slightly less than the $1.5 \mathrm{mg} /$ day dose of caffeine we routinely administer long-term to $\mathrm{AD}$ mice. This theophylline dosage presumably resulted in plasma theophylline levels at least as high as those resulting from chronic caffeine administration because AD mice chronically treated with caffeine have a plasma caffeine-to-theophylline ratio of approximately 8-to1 [13].

At 6 months into theophylline treatment, mice were evaluated in our standard 6-week behavioral battery of sensorimotor, anxiety, and cognitive-based tasks, as 

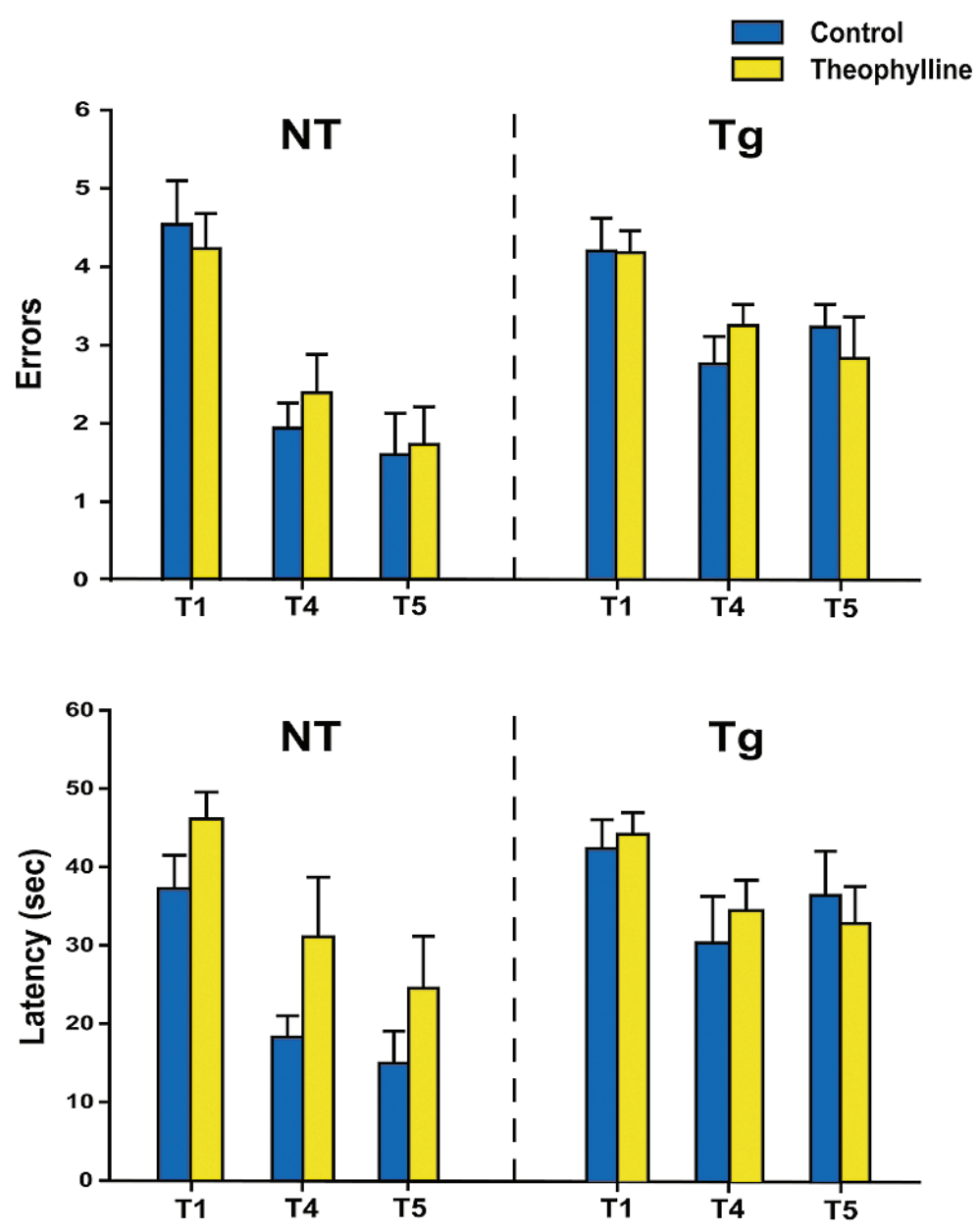

Fig. 2. Inability of long-term treatment with the active caffeine metabolite theophylline to provide cognitive benefit to AD transgenic mice or non-transgenic littermates, as demonstrated by the radial arm water maze task of working memory. The data presented are for Trial 1 (naïve first trial), and Trials 4 and 5 (working memory trials) overall across 12 days of testing at 6 months into theophylline treatment. The number of animals in each group were: NT controls $(n=7)$, NT+theophylline $(n=8)$, Tg controls $(n=7)$, and Tg+theophylline $(n=9)$.

done in our initial caffeine study [11]. Across multiple cognitive-based tasks [Y-maze spontaneous alternation, Morris maze acquisition/retention, circular platform, platform recognition, and radial arm water maze], there were no effects of theophylline treatment in either $\mathrm{Tg}$ or non-transgenic mice compared to controls. An example of this surprising lack of cognitive benefit with long-term theophylline treatment is shown in Fig. 2 for the radial arm water maze task of working memory. For both errors and latency during working memory trials $\mathrm{T} 4$ and $\mathrm{T} 5$, theophylline-treated mice performed no different from controls across 12 days of testing. In addition, there were no effects of theophylline treatment on sensorimotor tasks (open field activity, balance beam, string agility) or on the elevated plus-maze task of anxiety (data not shown). Thus, we conclude that the cognitive benefits of caffeine administration in our prior protection-based [11] and treatment-based [12] studies were likely due to caffeine itself, and not theophylline. Whether or not the other major caffeine metabolite (paraxanthine) may be responsible for some of caffeine's cognitive benefits in $\mathrm{Tg}$ mice remains to be determined.

It is important to put our long-term theophylline treatment study ( $>7$ months of treatment) in proper context of prior work investigating theophylline's effects on cognitive function. Our search of the scientific literature has, firstly, revealed a wealth of studies showing no effect of theophylline administration on the cognitive performance of humans (both adults and children). This is consistent with our present finding of long-term theophylline treatment having no cognitive 


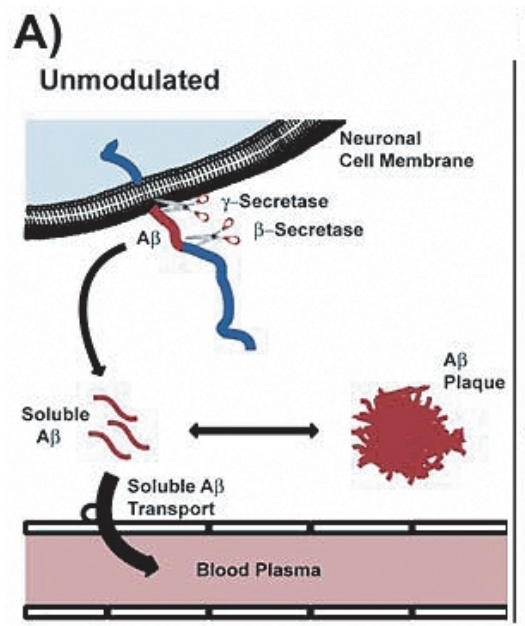

B)

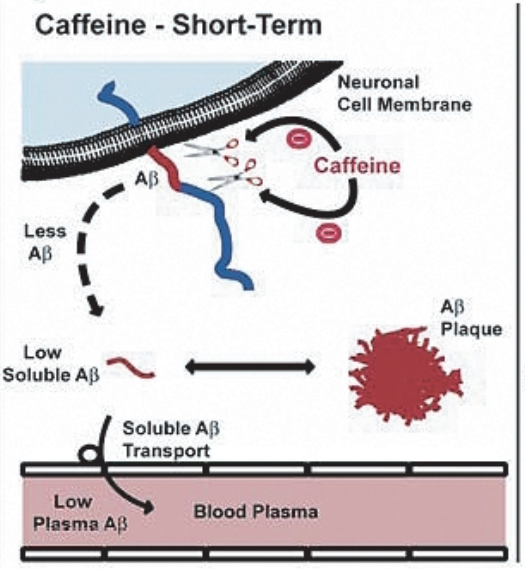

C)

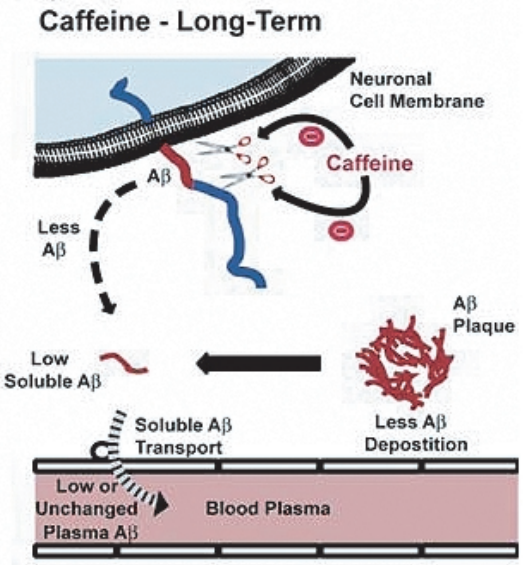

Fig. 3. Brain $\mathrm{A} \beta$ production/clearance, the suppressive actions of caffeine on $\mathrm{A} \beta$ production, and resultant effects on brain and plasma $\mathrm{A} \beta$ levels. (A) Unmodulated: A $\beta$ is primarily produced in neurons, secreted into the brain extracellular space in soluble form, then enters a dynamic equilibrium between soluble and deposited (insoluble) A $\beta$. Continual transport of soluble A $\beta$ occurs into plasma. (B) Caffeine: Short-Term: Caffeine suppression of both $\beta$ - and $\gamma$-secretase activities reduces $\mathrm{A} \beta$ production, resulting in lower soluble $\mathrm{A} \beta$ in brain and plasma. The equilibrium between soluble and deposited $\mathrm{A} \beta$ is not impacted by this short-term reduction in brain soluble $\mathrm{A} \beta$ levels. (C) Caffeine: Long-Term: Continuous caffeine suppression of $\mathrm{A} \beta$ production and resultant chronically lower levels of brain soluble $\mathrm{A} \beta$ induce a flux of deposited (insoluble) $\mathrm{A} \beta$ to the soluble form, which is cleared from brain into plasma via soluble $\mathrm{A} \beta$ transport. Plasma $\mathrm{A} \beta$ levels may be reduced or not changed, depending on degree of caffeine-induced suppression of $\mathrm{A} \beta$ production. Reproduced with permission from IOS Pres.

effects in normal mice across multiple tasks and cognitive domains. Secondly, no studies had investigated the effects of "long-term" theophylline on cognitive function prior to our present work. Earlier studies only involved "acute/single treatment" theophylline administration to normal mice or as a pre-treatment to mice exposed to a noxious stimulus (e.g., ischemia, microwave irradiation). Particularly since acute administration of caffeine (and presumably theophylline) may have cognitive effects that are different from long-term administration, the behaviorally-based theophylline study that we present in the current manuscript appears to be the first long-term theophylline treatment study investigating cognitive performance in any rodent, either normal, genetically-manipulated, or CNS-injured.

\section{Acute effects of caffeine/coffee on blood A $\beta$ levels in AD mice and humans}

Following formation of monomeric $\mathrm{A} \beta$ in the brain, newly produced $\mathrm{A} \beta$ enters into a dynamic equilibrium between soluble and deposited $\mathrm{A} \beta$ in the brain, with continual transport of soluble $\mathrm{A} \beta$ out of the brain and into plasma down a concentration gradient (Fig. 3A). Therefore, blood levels of $\mathrm{A} \beta$ may be indicative of caffeine's therapeutic actions on brain levels of $A \beta$. In view of our findings that caffeine decreases $\mathrm{A} \beta$ production in AD transgenic mice through suppression of both $\beta$ - and $\gamma$-secretase $[11,12]$, we have hypothesized that ensuing lower brain levels of soluble $\mathrm{A} \beta$ will result in lower plasma $\mathrm{A} \beta$ levels acutely (Fig. $3 \mathrm{~B}$ ). This hypothesis is supported by the finding that $A \beta$ is rapidly produced and cleared from the brain [20]. Moreover, following almost 2 months of caffeine administration to "aged" Tg transgenic mice (see preceding section), we have found that higher plasma caffeine levels were strongly associated with lower plasma $\mathrm{A} \beta$ levels in individual Tg mice $(r=-0.761 ; p=0.011)$.

Considering the above findings, we determined the effects of acute caffeine [13] or coffee administration on plasma and brain $\mathrm{A} \beta$ levels in $\mathrm{AD}$ transgenic mice. Acute (single treatment) administration of caffeine $(1.5 \mathrm{mg} / 0.2 \mathrm{cc})$ or saline vehicle was given by i.p. injection or gavage to $\mathrm{A} \beta \mathrm{PPsw}$ transgenic (Tg) mice in young adulthood ( 3 months old) or in older age (14 months old). At 3 hours following treatment, plasma $\mathrm{A} \beta_{1-40}$ levels in 3-month old Tg mice were substantially reduced by $41 \%$. Even the older 14-month old Tg mice showed significant reductions in plasma $\mathrm{A} \beta$ following acute caffeine treatment. We have since repeated these studies in additional $\mathrm{Tg}$ mice, acutely administering caffeinated or de-caffeinated coffee (i.p.) instead of caffeine (Caffeinated coffee contained the same $1.5 \mathrm{mg}$ caffeine/ $0.2 \mathrm{cc}$ as in pure caffeine administration). At 3 hours following an initial treatment and 3 hours after another treatment 3 days later, caffeinated 


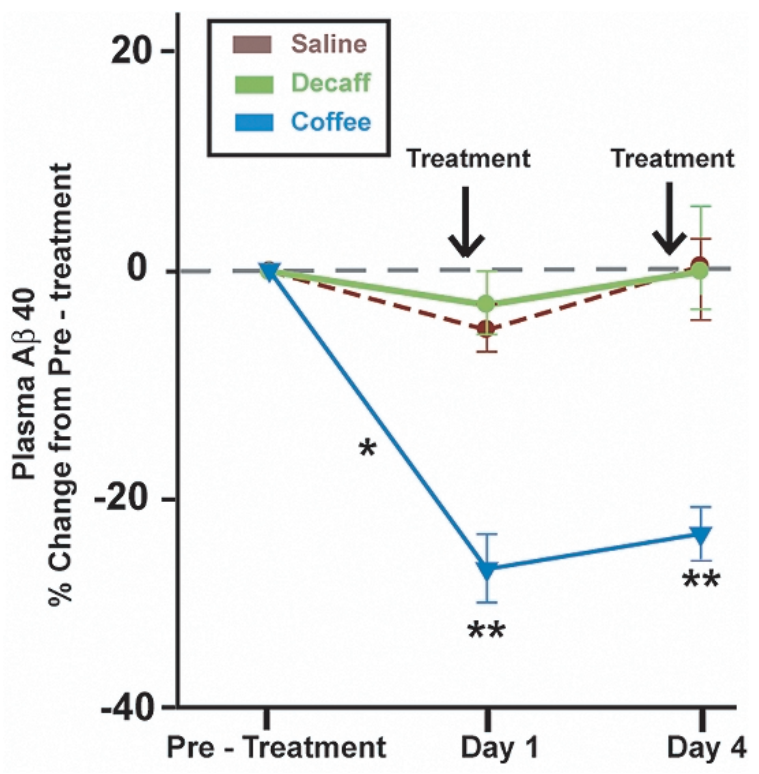

Fig. 4. Ability of (caffeinated) coffee to acutely suppress plasma $\mathrm{A} \beta$ levels, but not de-caffeinated coffee or saline control. Treatments (i.p.) were administered on Days 1 and 4, 3 hours prior to taking a blood sample on both days. Percent change from pre-treatment $\mathrm{A} \beta$ levels are graphed. Each group consisted of 6-7 A $\beta$ PPsw mice. ${ }^{*} p<0.02$ for Pre vs. Day 1 , coffee group only; ${ }^{* *} p<0.02$ for coffee group vs. other two groups on that day. Absolute values (in $\mathrm{pg} / \mathrm{ml}$ ) for pre - versus post-treatment (Day 1) plasma A $\beta_{1-40}$ levels and associated paired $t$-test statistics were: Saline treatment $(6055 \pm$ 1180 vs. $5400 \pm 381$, N.S.), Decaffeinated coffee (6036 \pm 1029 vs. $5662 \pm 809$, N.S.), Caffeinated coffee (6851 \pm 1446 vs. $5090 \pm$ $637, p<0.02)$

coffee provided the same beneficial reduction in plasma $\mathrm{A} \beta-40$ levels as we had previously reported for pure caffeine (Fig. 4). By contrast, decaffeinated coffee and saline treatments had no effect on plasma $\mathrm{A} \beta_{1-40}$ levels. Thus, caffeine is the likely coffee constituent that is critical for decreasing brain and plasma $\mathrm{A} \beta$ levels. Although this acute study did not involve measurement of "brain" $\mathrm{A} \beta$ levels as in our prior acute and long-term studies [11-13], the fact that acute caffeine administration in our prior work resulted in reductions in both plasma and brain $A \beta$ levels within the same 2-3 hour time course [13] strongly suggests that a similar reduction in brain $\mathrm{A} \beta$ occurred with coffee administration, but not with decaffeinated coffee administration.

In a separate group of 3-month old Tg mice, measurement of brain interstitial fluid (ISF) levels of $\mathrm{A} \beta$ through in vivo microdialysis was performed both before and following caffeine administration $(1 \mathrm{mg}$, i.p.). This single caffeine treatment significantly lowered brain ISF A $\beta$ levels by $32 \%$ at $2-3$ hours posttreatment, compared to the basal ISF A $\beta$ levels in each mouse [13]. Follow-up studies showed that this rapid suppression of brain $\mathrm{A} \beta$ levels by caffeine was not due to increased $\mathrm{A} \beta$ elimination from the brain, but rather was due to decreased $\mathrm{A} \beta$ production. These acute studies collectively indicate that plasma $\mathrm{A} \beta$ can be a viable biomarker for the efficacy of anti-A $\beta$ therapeutics such as caffeine. It is nonetheless important to underscore that our acute caffeine administration studies involved AD transgenic mice "naïve" to caffeine, whereas any clinical trials in humans would involve many occasional or habitual caffeine users.

As a clinical extension of our studies in AD mice and in view of the aforementioned clinical caveat, we have embarked on acute caffeine and coffee administration studies in humans. Similar to our AD mouse studies, we find that acute oral caffeine administration (400 mg) to aged humans induces an immediate decrease in blood $\mathrm{A} \beta$ levels in approximately half of subjects (data not shown). In both young adult and aged humans, we find that blood $\mathrm{A} \beta$ levels continue to be modified many hours following caffeine or coffee administration. These initial clinical studies are consistent with caffeine/coffee having an immediate and direct effect on what could be the primary pathogenic mechanism of AD. Inasmuch as the protocols and results of these acute caffeine administration studies will be presented in detail within upcoming manuscripts, they should currently be considered as preliminary observations that suggest a similar response of human and mouse subjects to acute caffeine administration. Additional clinical studies are underway to determine more long-term effects of caffeine and coffee administration to aged humans and AD patients.

\section{DISCUSSION}

The results of our studies indicate a surprising ability of moderate caffeine intake to protect against or reverse AD-like cognitive impairment and $\mathrm{A} \beta$ neuropathology in established mouse models for AD. The equivalent amount of daily caffeine intake that our studies suggest is required for human therapeutic benefit against $\mathrm{AD}$ is approximately $500 \mathrm{mg}$. The average US intake of caffeine is only around $150 \mathrm{mg} /$ day and decreases during aging - thus, average caffeine intake appears to be significantly below levels necessary for benefits against AD. An 8 oz. cup of coffee contains $100 \mathrm{mg}$ caffeine, while a similar serving of tea or soft drinks contain only 35 and $25 \mathrm{mg}$ caffeine, respectively. As such, only five cups of coffee per day (a moderate con- 
sumption level) are needed to reach the $500 \mathrm{mg}$ level, while many more servings of tea or soft drinks would be required. Moreover, given coffee's significant content of antioxidants and other beneficial phytochemicals, this source of caffeine is clearly preferable over essentially any other source.

Caffeine's beneficial effects against cognitive impairment and AD neuropathology probably involve first and foremost the unique ability of caffeine to suppress both enzymes needed for brain $\mathrm{A} \beta$ generation, namely $\beta$-secretase and $\gamma$-secretase. Nonetheless, multiple other mechanisms are probably contributing to the therapeutic actions of caffeine in AD animal models, including caffeine's ability to act as: 1) a strong antiinflammatory agent, 2) an anti-oxidant, 3) a mitochondrial activator, and 4) a stimulator of both neuronal activity and glucose utilization. Although adenosine receptor antagonism should certainly be included in this list, caffeine's actions almost certainly do not involve simply the increase in alertness provided by such receptor blockade. Indeed, if this were a primary mechanism of caffeine's cognitive benefit, normal mice should have benefited cognitively from a lifetime of caffeine administration, but this was not the case [12]. Thus, we propose that caffeine does not act as a general nootropic agent to enhance "normal" cognitive performance. Rather, we believe that caffeine protects against and minimizes brain cognitive impairment, such as that due to brain $A \beta$ accumulation/aggregation in $A D$.

Studies in this paper present evidence that caffeine is providing cognitive benefits to $\mathrm{AD}$ transgenic mice directly, since a major active metabolite of caffeine (theophylline) was found to be cognitively ineffective. It is important to note, however, that our theophylline administration studies utilized mice of a different transgenic line (A $\beta$ PPsw + PS1), bearing a different strain background (C57/BL6), and obtained from a commercial breeder (Jackson Laboratories). By contrast, all of our other behavioral studies with caffeine administration [11-13] involved inbred mice of our own transgenic colonies. We have previously determined that $\mathrm{A} \beta \mathrm{PPsw}$ or A $\beta$ PPsw + PS1 mice on a C57/BL6 background (e.g., those from commercial breeders) require considerably longer aging (compared to our inbred mice on a mixed C57/BL6/SW/SJL background) before cognitive impairment becomes apparent. Thus, it is possible that results of this study could have been different had we utilized mice of our own inbred colonies and/or began the study with aged, alreadyimpaired transgenic mice for examining the effects of theophylline administration on cognitive function.
If the inability of long-term theophylline administration to mimic the therapeutic effects of caffeine is independent of the AD mice and treatment paradigm utilized (as we suspect is the case), this would argue for such benefits of caffeine to be independent of adenosine receptors. Supportive of this premise, theophylline is 3 to 5 times more potent than caffeine as an antagonist of both adenosine $\mathrm{A} 1$ and $\mathrm{A} 2 \mathrm{a}$ receptors. Alternatively, it is possible that brain theophylline levels (which we did not measure in this study) in theophylline-treated Tg mice were insufficient for providing behavioral and neuropathologic benefit. Either scenario would be consistent with a mechanism that does not primarily involve adenosine receptor antagonism.

In our "acute" studies, AD mice given a single treatment with caffeine exhibited quick reductions in both brain interstitial fluid and plasma $\mathrm{A} \beta$ levels (i.e., within 2-3 hours). Since caffeine did not affect the half-life of ISF $\mathrm{A} \beta$, caffeine had directly affected brain $\mathrm{A} \beta$ production rather than its elimination. Underscoring this premise are our findings that caffeine affects $\mathrm{A} \beta$ production through suppression of both $\beta$-secretase (BACE1) and $\gamma$-secretase/PS1 expression $[11,12]$. Acutely, this caffeine-induced decrease in $\mathrm{A} \beta$ production would result in lower soluble $\mathrm{A} \beta$ in brain ISF and consequently lower plasma $\mathrm{A} \beta$ levels (Fig. 2, Caffeine - Short-Term). This is exactly what we observed in AD mice that were young adults (with no brain $\mathrm{A} \beta$ deposition), as well as aged $\mathrm{AD}$ mice (bearing robust $\mathrm{A} \beta$ deposition). Whether or not this caffeine-induced suppression of $\mathrm{A} \beta$ production is direct or involves adenosine receptor blockade/mediation is currently unknown. Evidence against involvement of adenosine receptors is provided by studies showing that acute and chronic caffeine administration to mice given noxious brain conditions (e.g., ischemia, excitotoxin exposure) results in opposite effects (worse or lesser damage) due to antagonism of A1 and A2a receptors, respectively [21]. In sharp contrast, both acute and chronic caffeine administration decrease plasma and brain $\mathrm{A} \beta$ levels.

In our long-term "treatment" study in aged/cognitively-impaired AD mice, caffeine reversed their working memory impairment. This 2-month caffeine administration regime not only reduced brain soluble $\mathrm{A} \beta$ levels, but also reversed brain $\mathrm{A} \beta$ neuropathology. Although the mechanism(s) for caffeine-induced reversal of $\mathrm{A} \beta$ deposition requires further investigation, we hypothesize that "chronic" caffeine suppresses A $\beta$ production long-term, resulting in consistently lower brain levels of soluble ISF A $\beta$ (Fig. 2, Caffeine-Long-Term). This 
would then induce a flux of insoluble $\mathrm{A} \beta$ out of the deposited form and into the soluble form due to dynamic equilibrium. Newly-solubilized $\mathrm{A} \beta$ would then be cleared into the plasma via both blood-brain-barrier transport and bulk fluid flow. The dynamic equilibrium between soluble (ISF) and insoluble/deposited $\mathrm{A} \beta$ in the brain is underscored by previous work showing that young adult and aged $\mathrm{A} \beta \mathrm{PP}$ sw mice had similar steady-state levels of ISF $\mathrm{A} \beta$, but rapid inhibition of $\mathrm{A} \beta$ production resulted in a two-fold longer $\mathrm{A} \beta$ half-life in the aged, $\mathrm{A} \beta$ deposit-bearing mice [22]. We believe this longer $\mathrm{A} \beta$ half-life is caused by solubilization of a portion of the deposited $\mathrm{A} \beta$ pool due to the dynamic ISF $\mathrm{A} \beta \leftrightarrow$ deposited $\mathrm{A} \beta$ equilibrium.

The effects of "chronic" caffeine intake on health have been reported in numerous retrospective and prospective studies. A comprehensive review of the literature [23] found that for healthy adults, moderate daily caffeine intake poses no adverse effects on the cardiovascular system, bone status and calcium balance, or incidence of cancer. Prospective studies have not found significant associations between coffee consumption and the risk of coronary heart disease [24, 25]. Contrary to public belief, caffeine intake of 500$600 \mathrm{mg}$ daily does not increase the risk, frequency, or severity of cardiac arrhythmias [26,27]. Indeed, there is a growing list of age-related diseases wherein habitual caffeine intake of 400-600 mg (4-6 cups of coffee) daily reduces the risk. For example, strong data from a number of prospective studies show that both caffeine and coffee reduce the risk of Type 2 Diabetes Mellitus by $35-79 \%$ [28]. Both retrospective and prospective studies report a reduced risk of Parkinson's disease with habitual caffeine/coffee intake [29,30]. Risk of liver cirrhosis is significantly reduced by both caffeine and coffee [31]. Thus, far from posing a threat to human health during aging, habitual caffeine/coffee intake provides a number of health benefits.

Finally, it should be underscored that "acute" effects of caffeine or coffee administration on plasma $\mathrm{A} \beta$ levels clearly occur in both AD mouse models and humans. This suggests not only that these mouse models are providing valuable insight into development of therapeutics against $\mathrm{AD}$, but also that blood levels of $\mathrm{A} \beta$ could be a monitor for anti-A $\beta$ therapeutic effects occurring in the brain, such as with caffeine. An exciting period of clinical research with caffeine and coffee against $\mathrm{AD}$ is on the horizon. This research may finally show that a safe and readily available natural agent caffeine - provides the first effective therapeutic against AD.
In summary, our studies utilized AD transgenic mice to demonstrate that: 1) Caffeine protects $\mathrm{AD}$ mice against memory loss through mechanisms that directly affect the disease process, 2) Caffeine reverses memory loss and AD pathology in "aged" AD mice, and 3) Caffeine and/or caffeinated coffee both affect plasma levels of $\mathrm{A} \beta$ in $\mathrm{AD}$ mice and humans. Our results warrant the clinical trials in progress with caffeine and caffeinated coffee as safe, inexpensive, and effective therapeutics against AD.

\section{ACKNOWLEDGMENTS}

The following collaborators in these studies are gratefully acknowledged: Valentina Echeverria, John Cirrito, David Holtzman, Huntington Potter, Takashi Mori, Maggie Mamcarz, Melissa Runsfeldt, Li Wang, William Schleif, Edwin Jackson, Jennifer Cracchiolo, Daniel Shippy, Alexander Dickson, Ashok Raj, Kavon Rezia-Zadeh, Jun Tan, Bruce Citron, Xiaoyang Lin, and Chi Zhang. This work was supported by NIH grant AG025711 and funds from the Byrd Alzheimer's Center and Research Institute.

Authors' disclosures available online (http://www.jalz.com/disclosures/view.php?id=242).

\section{REFERENCES}

[1] Jarvis M (1993) Does caffeine intake enhance absolute levels of cognitive performance? Psychopharmacol 110, 45-52.

[2] Hameleers P, van Boxtel M, Hogervorst E, Riedel W, Houx P, Buntinz F, Jolles J (2000) Habitual caffeine consumption and its relation to memory, attention, planning capacity, and psychomotor performance across multiple age groups. Human Psychopharmacol 15, 573-581.

[3] Lorist M, Snel J, Mulder G (1995) Aging, caffeine, and information processing: an event-related potential anlaysis. Electroencephal Clin Neurophysiol 96, 453-467.

[4] van Gelder B, Buijsse B, Tijhuis M, Kalmijn S, Giampaoli S, Nissinen A, Kromhout D (2007) Coffee consumption is inversely associated with cognitive decline in elderly European men: the FINE Study. Eur J Clin Nutr 61, 226-232.

[5] Ritchie K, Carrière I, de Mendonça A, Portet F, Dartigues J, Rouaud O, Barberger-Gateau P, Ancelin M (2007) The neuroprotective effects of caffeine: a prospective population study (the Three City Study). Neurology 69, 536-545.

[6] Eckelinen M, Ngandu T, Tuomilehto J, Soininen H, Kivipelto M (2009) Midlife coffee and tea drinking and the risk of latelife dementia: A population-based CAIDE study. J Alzheimers Dis 16, 85-91.

[7] Maia L, de Mendonça A (2002) Does caffeine intake protect from Alzheimer's disease? Eur J Neurol 9, 377-382. 
[8] Arendash G, Lewis J, Leighty R, McGowan E, Cracchiolo J, Hutton M, Garcia M (2004) Multi-metric behavioral comparison of APPsw and P301L models for Alzheimer's disease: linkage of poorer cognitive performance to tau pathology in forebrain. Brain Res 1012, 29-41.

[9] Arendash G, Garcia M, Costa D, Cracchiolo J, Wefes I, Potter H (2004) Environmental enrichment improves cognition in aged Alzheimer's transgenic mice despite stable beta-amyloid deposition. Neuroreport 15, 1751-1754.

[10] Cao C, Arendash G, Dickson A, Mamcarz M, Lin X, Ethell $D$ (2009) A $\beta$-specific Th2 cells are sufficient to reverse cognitive impairment, cerebral angiopathy, and pro-inflammatory profiles in Alzheimer's transgenic mice. Neurobiol Dis 34, 63-70.

[11] Arendash G, Schleif W, Rezai-Zadeh K, Jackson E, Zacharia L, Cracchiolo J, Shippy D, Tan J (2006) Caffeine protects Alzheimer's mice against cognitive impairment and reduces brain beta-amyloid production. Neuroscience 142, 941-952.

[12] Arendash G, Mori T, Cao C, Mamcarz M, Runfeldt M, Dickson A, Rezai-Zadeh K, Tan J, Citron B, Lin X, Echeverria V, Potter H (2009) Caffeine reverses cognitive impairment and decreases brain $\mathrm{A} \beta$ levels in aged Alzheimer's mice. $J$ Alzheimers Dis 17, 661-680.

[13] Cao C, Cirrito J, Lin X, Wang L, Verges D, Dickson A, Mamcarz M, Zhang C, Mori T, Arendash G, Holtzman D, Potter $\mathrm{H}$ (2009) Caffeine suppresses $\beta$-amyloid levels in plasma and brain of Alzheimer's transgenic mice. J Alzheimers Dis 17, 681-697.

[14] Horrigan L, Kelly J, Connor T (2006) Immunomodulatory effects of caffeine: Friend or foe? Pharmacol Ther 111, 877 892.

[15] Azam S, Hadi N, Khan N, Hadi S (2003) Antioxidant and prooxidant properties of caffeine, theobromine and xanthine. Med Sci Monit 9, 325-330.

[16] Chen X, Gawryluk J, Wagener J, Ghribi O, Geiger JD (2008) Caffeine blocks disruption of blood brain barrier in a rabbit model of Alzheimer's disease. J Neuroinflammation 5, 12.

[17] Dall'Igna O, Fett P, Gomes M, Souza D, Cunha R, Lara D (2007) Caffeine and adenosine A2A receptor antagonists prevent beta-amyloid (25-35)-induced cognitive deficits in mice. Exp Neurol 203, 241-245.

[18] Cunha G, Canas P, Melo C, Hockemeyer J,Müller C, Oliveira C, Cunha R (2008) Adenosine A2A receptor blockade prevents memory dysfunction caused by beta-amyloid peptides but not by scopolamine or MK-801. Exp Neurol 210, 776-781.

[19] Johansson B, Georgiev V, Kuosmanen T, Fredholm B (1996) Long-term treatment with some methylxanthines decreases the susceptibility to bicuculline- and pentylenetetrazol-induced seizures in mice. Relationship to c-fos expression and receptor binding. Eur J Neurosci 8, 2447-2458.

[20] Bateman R, Munsell L, Morris J, Swarm R, Yarasheski K, Holtzman D (2006) Human amyloid-beta synthesis and clearance rates as measured in cerebrospinal fluid in vivo. Nat Med 12, 856-861.

[21] Cunha RA (2005) Neuroprotection by adenosine in the brain: From A1 receptor activation to A2A receptor blockade. Purinergic Signal 1, 111-134.

[22] Cirrito J, May P, O'Dell M, Taylor J, Parsadanian M, Cramer J, Audia J, Nissen J, Bales K, Paul S, DeMattos R, Holtzman D (2003) In vivo assessment of brain interstitial fluid with microdialysis reveals plaque-associated changes in amyloidbeta metabolism and half-life. $J$ Neurosci $\mathbf{2 3}, 8844-8853$.

[23] Nawrot P, Jordan S, Eastwood J, Rotstein J, Hugenholtz A, Feeley M (2003) Effects of caffeine on human health. Food Addit Contam 20, 1-30.

[24] Myers M, Basinski A (1992) Coffee and coronary heart disease. Arch Intern Med 152, 1767-1772.

[25] Kawachi I, Colditz G, Stohne C (1994) Does coffee drinking increase the risk of coronary heart disease? Br Heart $\mathrm{J} \mathbf{7 2}$, 269-275.

[26] Myers M (1991) Caffeine and cardiac arrhythmias. Ann Intern Med 114, 147-150.

[27] Frost L, Vestergaard P (2005) Caffeine and risk of atrial fibrillation or flutter. Am J Clin Nutri 81, 578-582.

[28] Higdon J, Frei B (2006) Coffee and health: a review of recent human research. Crit Rev Food Sci Nutr 46, 101-123.

[29] Ross G, Abbott R, Petrovitch H (2000) Association of coffee and caffeine intake with the risk of Parkinson's disease. JAMA 283, 2674-2679.

[30] Hernan M, Takkouche B, Caamano-Isoma F (2002) A metaanalysis of coffee drinking, cigarette smoking, and the risk of Parkinson's disease. Ann Neurol 52, 276-284.

[31] Ruhl C, Everhart J (2005) Coffee and caffeine consumption reduce the risk of elevated serum alanine aminotransferase activity in the United States. Gastroenterol 128, 24-32. 